\title{
STRATEGIC PLANNING FOR SUSTAINABLE BIOSPHERE RESERVES MANAGEMENT THROUGH CBMS PROGRAM
}

\author{
Mahmood Yekeh Yazdandoost \\ Department of Environment (DoE), Iran \\ Email: yazdandoost3000@gmail.com
}

\begin{abstract}
The program focuses on developing and implementing models for Sustainable Biosphere Reserves Management (SBRM) through collaboration and participation of stakeholders including local communities and indigenous people based on Community- Based Management System (CBMS) model. The biosphere reserves would be protected to serve as monitoring and learning sites for environmental professionals, decision makers, scientific societies, management practitioners and stakeholder communities to work together to decode global principles and complexities of sustainable development into locally relevant and acceptable activities.
\end{abstract}

Key words: Sustainable Biosphere Reserve Management, Capacity Building, Mainstreaming

\section{Introduction}

Community-Based Management System (CBMS) is to protect human health and to safeguard the natural environment like; air, water and land upon which life depends. CBMS is one approach that can help the National Environment Committee (NEC) to fulfill this mission. The CBMS approach emphasizing comprehensive community-based solutions, like; reducing health and environmental risks, maximizing public participation and strengthening partnerships. UNESCO Biosphere Reserves are currently defined as "living laboratories for sustainable development" and are the only sites under the United Nations system that call for conservation and sustainable development to proceed along mutually supportive paths (Meijaard, 2010). Each Biosphere Reserve Intend to Fulfill Three Complementary Functions (UNESCO, 2011):

1. A conservation function, to preserve genetic resources, species, ecosystems and landscapes;

2. A development function, to foster sustainable social and economic development; and,

3. A logistic support function, to support demonstration programs, environmental research, monitoring, education and training, national and global issues of conservation and sustainable development.

In sum, biosphere reserves should preserve and generate natural, indigenous and cultural values, through integrated management that is scientifically appropriate, culturally creative and operationally sustainable. Engagement processes and practices in which a wide range of people work together to achieve a shared goal guided by a commitment to a common set of values, principles and criteria (Aslin and Brown, 2004). To cooperate within a process is to have each party contribute what they can in order to best serve their needs in a mutually beneficial way (Benaim, et al., 2008). The program focuses on developing and implementing models for Sustainable Biosphere Reserves Management (SBRM) through collaboration and participation of stakeholders including local communities and indigenous people based on Community-Based Management System (CBMS) model.

The key focal persons or groups on biosphere reserves' management should be the catalyst for this process, supported by the national coordinating mechanism on biosphere reserves. Stakeholders are rural people, civil society, private sectors, national academia, research institutions, media and government ministries and departments. The various roles for each participant groups should be clarified by stakeholder analysis approach through collaborative management and coordinated agreement. Strategies should identify specific policies on biosphere reserves and also examine how biosphere reserves are addressed through other national policies, programs and national budgets. This involves assessing how far biosphere reserves are being mainstreamed and looking at how this could be taken forward. 
The focus for bottom-up approach should then be decided upon. The CBMS model expected to firmly promote:

- Biosphere reserves integration into conservation planning and programming;

- Better harmonization and integration among the different biosphere reserves zones;

- Knowledge of the interactions between humans and the biosphere; and,

- Mainstreaming local environmental management into Poverty Reduction Strategy Papers(PRSP)

Active community engagement would foster local ownership and common purpose, enhance protected areas acceptance, and facilitate the emergence of cooperative, adaptive, accountable and consensual conservation management (Stoll-Kleemann, et al., 2010).

\section{The CBMS Advantages}

- It is responsive to unique community characteristics. CBMS addresses problems where they arise and where the so Mainstreaming local environmental management into Poverty Reduction Strategy Papers (PRSP) established;

- Pools stakeholder resources. Rather than having a dozen separate organizations pursue distinct environmental goals, CBMS brings those organizations together, to pool resources to achieve common goals.

- Minimizes duplicate efforts. CBMS brings multi environmental programs together in places of work, to find comprehensive solutions for problems.

- Builds infrastructure for problem solving. CBMS helps build a sense of stewardship and community infrastructure for environmental problem solving.

Investment role in any given CBMS effort may range from education to technical assistance or otherwise to a leadership and banking system support. The following interests drive the degree of National involvement in CBMS efforts:

- Statutory requirement. CBMS promotes communities to meet their regulatory requirements;

- Ecological and human health risks. If a community faces exceptional ecological or human health risks or if a community has natural resources of national significance, National Environmental Committee (NEC) may become involved in a CBMS effort to address the underlying environmental problems and to protect natural resources.

- Community needs and desires. NEC may respond to a community's request for assistance and involvement in a CBMS effort.

\section{CBMS Vision}

CBMS vision is to support communities' efforts to use, protect and restore natural resources, like; land, air, water and biodiversity in ways that help ensure long-term ecological, economic, social and human health benefits for current and future generations.

\section{Methodology}

Facilitators with sufficient experience of participatory approach should be identified. Poor and marginalized communities should be selected for participation. For achievement the program should be followed by:

- Strengthening legal frameworks and the capacity of partners;

- Providing opportunities for interaction, training, education and scientific research;

- Enhancing delivery of the capacity building initiatives to local communities;

- Implementing the international agreed goals on Biosphere Reserves Management(BRM) to registered areas

The requirements for the above achievement are:

- Well defined community involvement;

- Links between conservation, health and development; and,

- International collaboration and investment

To move from primary conservation to greater environmental integration, increasing cooperation among all stakeholders would be necessary. 


\section{Results and Discussion}

The Community-Based Management System (CBMS) is an important approach because the economic and social impacts are inextricably linked to the environmental impacts, thus needs understanding and investment. The result indicates this approach needs a number of programs and initiatives that support the place-based and community driven efforts to address environmental issues:

- National training programs on environmental laws, including local training for trainers and workshops for provincial environmental experts;

- Country dialogues and implementation plans for community-level strategies to reduce the vulnerability of the indigenous people living in biosphere reserves areas;

- Workshops to provide technical support to environmental managers and experts in testing the ecosystem approaches on a National and local levels as strategic tools for integrated policy development;

- Capacity building workshops for civil society partners on development and implementation of National institutional frameworks for environmentally and socially sound green development mechanism programs;

- Pilot projects to develop and test adaptation models and institutional arrangements for increasing protection in biosphere reserves;

- Substantive inputs to mainstreaming of gender issues;

- Implementation of the processes in integrating the ecosystem components into Poverty Reduction Strategy Papers (PRSP);

- Seed funds to support sustainable development solutions;

- Assistance to communities that are disproportionately affected by environmental threats or do not have equal access to environmental benefits; and,

- Watershed approach as the geographic unit for harvesting and conservation.

Thus it is an integrating tool which can help to create greater solidarity and collaboration among individuals and nations of the world. Initially CBMS can be more time-consuming; in the longrun it can be more effective, more efficient and yield more enduring sustainable solutions for addressing our more challenging environmental problems than a strictly regulatory approach. Moreover investment on CBMS is cost-effective. While NEC may play any combination of roles, depending on the specific situation in a community, it is more likely to take a leadership role if a community requests NEC assistance with an ongoing effort. Also NEC must work with all partners in each community to determine appropriate roles. The following strategy suggests ways NEC can improve and maximize capacity building when it assumes less direct roles than being a full stakeholder in a community:

- NEC should build capacity in those organizations, groups, and individuals who can and will engage the CBMS approach in places. Because CBMS activities often are bottomup endeavors, these external parties include citizens, community groups, nonprofit organizations, associations, business and industries, as well as local and provincial governments; and,

- NEC capacity building tools should reflect and promote the CBMS principles in order to maximize their potential benefit to communities. NEC shall use three broad tools to build external capacity:

1. Data and information;

2. Training and technical assistance; and,

3. Grants

The NEC should assemble and deliver data and information in ways that effectively inform the community-based decision-making processes, motivate the NEC constituencies to protect the environment and support performer measurement. NEC must work to arm the public with information about their local environment and possible changes which may occur. NEC should work directly with stakeholders in designated priority places. For the purpose of this framework, "working directly with stakeholders" implies hands-on involvement by NEC:

1. as a leader among stakeholders; or,

2. as an active but equal stakeholder within a place, during the planning and implementation of a CBMS effort

In either role, NEC may provide direct and substantial assistance (e.g., providing fund, technical assistance and/or data and information) to other stakeholders within a place. Performance measures must indicate of measuring progress toward NEC-CBMS goals as well 
as achievement of the goals. As a result: NEC must strive to answer three basic questions about CBMS performances:

1. How much progress is NEC making in coordinating and integrating programs and activities to increase its effectiveness in supporting community environmental decision making?

2. How NEC helping communities to develop the tools and capacity necessary to be stewards of the human and natural resources?

3. Does CBMS achieving environmental results consistent with NEC's mission and base program goals?

\section{Some NEC-CBMS Performance Measurement Includes}

- Number of national laws and regulations developed, strengthened or integrated;

- The development of environmental law through participation of stakeholders implemented;

- The number of national policies and development strategies that incorporate the biosphere reserves sustainable development promoted;

- The number of national policies and sustainable development strategies developed;

- The number of GOs and NGOs that effectively participate at the national level in policy development increased; and,

- Inclusion of biosphere reserves objectives in resolutions, decisions, policy strategies, guidelines increased.

\section{CBMS National Implementation Strategies}

NEC will try to realize goals for CBMS by employing three principle strategies:

1. Reorient environmental programs to better support CBMS;

2. Build external capacities; and,

3. Work directly with stakeholders in places.

The effort should strive to make the NEC more responsive to the needs of specific geographic areas, and capacity building should include helping communities navigate the regulatory processes, as well as making non-regulatory tools available. Perhaps most important is a full range of stakeholders involvement in helping NEC policies and CBMS activities.

\section{NEC should improve staff skills and expertise through}

- More training in areas of social sciences, such as group facilitation and building consensus, cultural sensitivity, systems thinking, economics, goal settings and communicating ecological issues;

- Hiring new local staffs, developing new career tracks and obtaining greater access to outside experts, like; economists, sociologists, cultural anthropologists, biologists, Geographic Information System (GIS) specialists, and risk assessors and mediators.

In the CBMS approach, public organizations, private agencies and citizens monitor and evaluate environmental, social and economic conditions holistically on various geographic scales. These groups need to generate specific data and information, criteria and benchmarks, guidance materials, training and other technical tools to make sound environmental decisions which affect their communities. New tools and models that can integrate diverse amount of data and information (e.g., population, income levels, landscape cover, land use, biological diversity, multi-chemical exposure, comparative risk) and stimulate the results of community planning scenarios are required. In addition, tools and information are needed to identify, target and plan work in priority places. Communities also need measures and indicators of environmental, social and economic conditions to evaluate progress toward meeting their human health and ecological objectives.

\section{Recommendation}

- When applicable, include projects to strengthen and develop biosphere reserves into programs that to be initiated and funded under the convention of Biological Diversity and other multilateral conventions;

- Develop incentives for the conservation and sustainable use of natural resources and develop alternative means of livelihoods for local populations, when existing activities are limited or prohibited within the biosphere reserve; 
- Ensure that each biosphere reserves has an effective management policy and programming and the appropriate authority or mechanism to implement it;

- Develop a functional system of data management for rational use in research and monitoring within the premises of biosphere reserves;

- Mobilize international and private funds from businesses, NGOs and foundations, for the benefit of biosphere reserves; and,

- Build local capacity for the management of biosphere reserves, through environmental education and multi-media outreach to the wider community

\section{Conclusion}

The biosphere reserves would be protected to serve as monitoring and learning sites for environmental professionals, decision makers, scientific societies, management practitioners and stakeholder communities to work together to decode global principles and complexities of sustainable development into locally relevant and acceptable activities. Bottom up participatory approaches bring communities and stakeholders willingly together, in order to make this model feasible and promotes comprehensive learning and sharing of information. This generates knowledge for policy makers, supports action and promotes public awareness. In doing so, policies and programs are improved. Governance is enhanced, as social capital developed and people motivated, to organize and advocate for improvements of their own environmental policies, health and protection. Such an approach will enable:

- broadening investment on policies and programs relevant to information sources (in depth qualitative data to complement quantitative data );

- priority setting of policies and programs that reflect the interests of the primary stakeholders and beneficiaries; and,

- opportunities for marginalized participants, in analyzing and articulating their situations with other stakeholders

These programs will promote partnerships of work for realistic change and achievement.

\section{Acknowledgement}

All scientific literatures released by IUCN, UNESCO, UNEP, CBD and other agencies including Department of Environment that have been used in this research article are highly appreciated.

\section{References}

1. Aslin Heather J. and Valerie A. Brown, (2004) Towards Whole of Community Engagement: A PRACTICAL TOOLKIT. Canberra: Murray-Darling Basin Commission.

2. Benaim André, Amber C. Collins and Luke Raftis, (2008) The Social Dimension of sustainable Development: Guidance and Application. Thesis, Blekinge Institute of Technology.

3. Meijaard Erik, (2010) Lessons from Biosphere Reserves in the Asia-Pacific Region, And a Way Forward. Prepared for UNESCO Office, Jakarta.

4. Stoll-Kleeman S., A.C. De La Vega-Leinert and L. Schultz. (2010) The role of community participation in the effectiveness of UNESCO Biosphere Reserve management: evidence and reflections from two parallel global surveys. Environmental Conservation 37 (3): 227238.

5. UNESCO, (2011) Biosphere Reserves World Network - Ecological Sciences for Sustainable Development. http://www.unesco.org/new/en/naturalsciences/ environment/ ecologicalsciences/biosphere-reserves/worldnetwork-wnbr/ (accessed January 25, 2011). 